\title{
Comentário VIII
}

\section{Sobre o campo de visibilidade: entre o passado e o futuro'}

\section{Iara Lis Schiavinatto ${ }^{2}$}

Além de abordar questões capitais da cultura histórica que nos constitui, o artigo matiza o regime de historicidade que nos rege. Recupera esse conceito - regime de historicidade - de Hartog, que tanto remete a um alto significado e valor da historicidade, à temporalidade e suas modalidades, quanto à consciência desse campo histórico-historiográfico, intrínsecos aí os processos operacionais de memória-esquecimento. Em 1995, nos Annales, Hartog conceituou:

Qu'on me permette, ici, une digression et l'introduction de la notion de régime d'historicité. J'entends par là une formulation savante de l'expérience du temps qui, en retour, modèle nos façons de dire et de vivre notre propre temps. Um regime d'historicité ouvre et circonscrit un espace de travail et de pensée, il rythme l'écriture du temps, represente um "ordre" du temps, auquel on peut souscrire, ou au contraire (et le plus souvent) vouloir échapper, en cherchant à en élaborer um autre ${ }^{3}$.

Tal noção ultrapassa de vez o historicismo, a crença no progresso, o tempo vazio, homogêneo, linear, o evento como átomo, puro em si ${ }^{4}$. De minha parte, enfatizo a força, a abrangência, a operacionalidade e a validade da noção de regime de historicidade, pois assegura uma compreensão epistêmica das diferenças do saber histórico e sua cultura envolvida. Um regime de historicidade herda, de outro, suas práticas, conceitos, valores, ambições, objetos, e há inter-relações entre eles. A noção também contempla a dimensão cotidiana da cultura histórica que hoje perpassa as produções midiáticas, a arquitetura e o urbanismo, o patrimônio e os museus, as memórias de família e outros mais, ou seja, diferencia protagonistas, procedências e debates. $\bigcirc$ regime de historicidade, no entanto, não se poupa de indagar compreensões da cultura histórica no senso comum, sem homogeneizá-las.

\begin{abstract}
1. Agradeço o convite dos Anais do Museu Paulista para comentar com gosto e grande interesse este artigo.

2 Docente da Universidade Estadual de Campinas, Instituto de Artes, Departamento de Multimeios. E-mail: <iara lis@uol.com.br>.

3. François Hartog (1995, p. 1220. Destaco ainda as formas pelas quais Hartog dialoga com Reinhart Koselleck e, para conceituar regime de historicidade, recupera sua obra Le futur passé: contribution à la sémantique des temps historiques, publicada na França em 1990.

4. Há já uma notável tradição que desconstrói o historicismo e a fé no progresso, que abarca Nietzsche, Freud, Bergson, Proust, Walter Benjamim.
\end{abstract}



dispositivos do dever de memória, ver:John Urry (1999); Nestor G. Canglini (2000); David Lowenthal (1985)

7. François Hartog (2003).

8. François Hartog (2005).

9. Este debate atravessa Peter Burke em Testemunba Ocular, Carlo Ginzburg, o próprio Hartog e mesmo o sensível livro de Susan Sontag (2003). Hartog (2005a, p. 169) assim a resume:"Car il y a une histoire de la vision, ou, de façon plus large encore, du visible et de l'invisible, de leur organisation et de leur partage, changeant d'une époque à l'autre". A evidência significa (em uma tradição histórica e lingüística) signo, marca, prova, testemunho, marcando-se pela variedade e pelo deslizamento de sentidos. regime de historicidade contemporâneo evidencia, em nós, a expansão do presente rumo ao passado e ao futuro. $\bigcirc$ presente em si não se basta, busca conquistar o passado e o futuro, em um movimento contínuo, como se nada pudesse ser esquecido ou perdido. $\bigcirc$ presentismo parece onipresente e eterno, sem limites. $\bigcirc$ evento agora é produzido incessantemente por uma economia, principalmente midiática, do presente e, simultaneamente, o momento passado já é pensado enquanto histórico, sob a égide do arquivo, do patrimônio, dos museus, da memória. $\bigcirc$ presente deseja sua imediata historicização. Se há uma aceleração do tempo, ela coincide com uma vocação memorialista. A aceleração produz um vazio de passado que o dever de memória tenta compensar, sintetiza Beatriz Sarlo ${ }^{5}$. Desta maneira, reifica o dever de memória, cristalizando e, tantas vezes, congelando o evento e sua experiência vivida. Esta onipresença do presente nos seduz e engata-se à necessidade de (re)afirmar a memória por meio do patrimônio, do arquivo, do museu, do testemunho, da filmografia. Por sua vez, esses passaram a ter sua produção, circulação e divulgação descentralizadas e multiplicadas no cotidiano, indo do presencial ao virtual, do nacional ao transnacional, do um ao outro, do simultâneo ao diacrônico e assim por diante ${ }^{6}$.

Em contrapartida, tal interpretação também permite perceber especificidades de outros regimes de historicidade: a Odisséia de Ulisses, e a de Penélope, obcecada pelo marido desaparecido ${ }^{7}$ - tema caro à experiência política contemporânea a exemplo das Madres de Mayo, sem ser o mesmo -, ou os expedientes de escrita da história, em Políbio, para alcançar a ambição de fazer uma história geral, no caso do império romano ${ }^{8}$. Esta noção, logo, força-nos a pensar as relações entre Um e a Alteridade - relação fundamental no conjunto da obra de Hartog. Permite, ainda, interrogar-nos sobre os limites do nosso entendimento histórico e suscita um outro repertório de questões, por exemplo, as trajetórias e conceituações da evidência no campo da história ${ }^{9}$. $\bigcirc$ regime de historicidade nos faz ciente de vetos, limites, demarcações e obriga, em certa medida, a interrogar-se acerca deles; assim, simultaneamente, indagase a respeito da elaboração deste questionário e de sua organização. Desta maneira, assume-se como parti pris uma inquietação constante, que não pode ser resolvida ou abrandada, sob pena de esquecer-se de si ou perder-se. Ou seja, o regime de historicidade evoca a crítica quanto a seus procedimentos, suas escolhas e afirmações. E isto configura relações de poder. Nesta medida, o regime de historicidade enreda-se às práticas de conduta e da cultura política na qual se inscreve e atua. Daí, em parte, o tom do final do artigo remeter-nos de forma intensa para o nosso presente como único lugar onde podemos estar e ser e, não à toa, menciona propostas de leveza, rapidez, exatidão, multiplicidade e visibilidade ao se referir às Seis propostas para o próximo milênio de Calvino.

No âmbito desses nexos de sentido, Manoel trabalha a inscrição da imagem na cultura histórica, não como uma ilustração, documento reconhecível ou com o objetivo crucial de entender os significados das artes visuais. Persegue a constituição da imagem como um valor e uma chave de acesso, apreensão, 
compreensão e explicação de outras temporalidades; e das nossas condições no presente. Isto é, uma espécie de "como se escreve a história" com imagens. Tal qual Carlo Ginzburg, ele pergunta acerca do lugar da imagem, de suas várias entradas na cultura histórica como representação do passado e como este passado pode ser modulado - o antigo, o remoto, o cultuado, o religioso, o terrífico, o selvagem, o outro, para citar alguns. Em alguns ensaios, Ginzburg explora as relações da imagem com o culto cristão e a tradição judaica, sua aproximação e distinção do ídolo, os debates aí transcorridos entre os Antigos e os primeiros textos bíblicos ou, ainda, o nascimento da representação como manequim do corpo do rei morto, a longevidade e força desta categoria de representação ${ }^{10}$ na cultura política da monarquia moderna. Ou seja, a imagem penetrava no campo do conhecimento histórico, concorria com outras categorias (o ídolo, por exemplo), passando a constituir modos de relacionar experiências humanas (d)e temporalidades especificas, por exemplo, o passado, o antigo, a catástrofe, o on-line, o ao vivo. Ainda, pode, segundo Ginzburg, fazer-nos ver o que não se via. Em si, ela seria capaz de produzir conhecimento, tal qual no artigo centrado em Picasso em Relações de força ${ }^{11}$.

Na sociedade contemporânea - que se reconhece sob o imperialismo da visualidade -, em um mundo hiper-semiótico (vincado pela aproximação e condensação da percepção espaço-temporal, sobretudo através de imagens virtuais e midiáticas), interrogar-se sobre a imagem e seus lugares - para ficar no trocadilho com lugares da memória - parece parada obrigatória do historiador. Embora me pareça que Manoel considera a imagem mais pelo enfoque de uma história cultural e de uma história dos conceitos do que na esteira do topos que tenderia, no limite, a cristalizar de vez seus sentidos. Nesta direção, seu resumo enfatiza:

O presente artigo pretende investigar algumas estratégias contemporâneas de dar visibilidade ao passado, compreendendo-as como parte de um esforço social de culturalização do tempo.

Este questionário, por sua vez, evoca as relações delicadas, constitutivas e tensas entre o visível, o invisível e a visão e, em um jogo de correlações, remete à presença e à ausência. No tempo presente, a imagem adquiriu a capacidade ontológica de significar o próprio evento, ao se pensar no 11 de Setembro, considerado um evento irrefutável, altamente presenciado, extremamente imagético e midiático, globalizado, político e, estrategicamente, arquitetado para ser visto; e mortal. Ela também é problematizada na teoria do trauma, de Freud, pois o evento traumático está além da nossa capacidade de representação ${ }^{12}$ e caracteriza-se por uma repetição imagética, e incessante, da cena traumática na alma daquele que a viveu. $\bigcirc$ trauma fica na literalidade da recordação da própria cena traumática, impossibilitando que tal evento seja ultrapassado, encerrado no passado ou no tempo de antes.

Essa relação entre imagem e evento é nevrálgica, quanto aos limites da representação impostos pela experiência da Shoah ${ }^{13}$, na qualidade de um
10. Refiro-me aos artigos de Carlo Ginzburg (Representação;A palavra, a idéia, a coisa; Ecce; Sobre as raízes culturais da imagem do culto cristã; 2001).

11. Carlo Ginzburg (2002).

12 Márcio Seligmann-Silva ensina sobre o trauma, ferida na memória: O trauma, para Freud, é caracterizado pela incapacidade de recepção de um evento transbordan te - ou seja,como no caso do sublime, trata-se, aqui também, da incapacidade de recepção de um evento que vai além dos "limites" da nossa percepção e torna-se, para nós, algo sem-forma (NETROVSKI; SELIGAMANNSILVA, 2000, p. 84)

13. Prefiro este termo a Holocausto em função do seu caráter menos sacrificial. Destaco a natureza da experiência concentracionária a obra de Saul Friedlander (1992). 
14.Ver Primo Levi (1990), em especial, A memória da ofensa e Comunicar.

15.Ver, em Charles Baudelaire (1980), os poemas: Embriagai-vos (p.91), Perda daAuréola (p. 112), e o descanso, uma espécie de não choque, em Anywhere out of the world... (p. 117). Em Perda da Auréola, a condição moderna do poeta nasce desse choque, $\mathrm{em}$ que perde sua auréola:

"Meu caro, você bem conhece o meu pavor dos cavalos e das carruagens. Ainda há pouco, quando atravessava a toda a pressa o bulevar, saltitando na lama, através desse caos movediço onde a morte surge a galope de todos os lados a um só tempo, a minha auréola, num movimento precipitado, escorregou-me da cabeça e caiu no lodo do macadame. Não tive coragem de apanhá-la. Julguei menos desagradável perdera as minhas insígnias do que ter os ossos rebentados. De resto, disse com meus botões, há males que vêm para bem.Agora posso passear incógnito, praticar ações vis, e entregar-me à crápula, como os simples mortais. E aqui estou, igualzinho a você, como está vendo" (BAUDELAIRE, 1980, p. 112).

16. Cf. Otavio Guilherme Velho (1979, p. 12-13)

17. Beatriz Sarlo (2005) dedica-se ao estudo deste trauma. evento-limite que não pode e não consegue ser representado. Ele se encontra para além da nossa capacidade de imaginá-lo, e de representá-lo. Primo Levi sintetizou a necessidade de comunicar esse evento, bem como seu caráter de incredulidade, o quanto transborda a nossa imaginação e nossa capacidade de representação; desta maneira, nunca conheceremos este evento in totum ${ }^{14}$. A Shoah não pode ser reduzida ao meramente discursivo, pois isto comprometeria a nossa condição humana. Não se pode negar, todavia, o lugar-chave que ela desempenha em nossa contemporaneidade.

Neste espectro, tal acepção de imagem muitas vezes se coaduna à noção de evento-choque, matéria-prima da poesia de Baudelaire ${ }^{15}$, estudada por Walter Benjamim, entre outros, em Alguns temas em Baudelaire, e explicada por Georg Simmel em A metrópole e a vida mental de 1902. Simmel alia o psiquismo do homem metropolitano, pleno de variantes, à imagem, à aceleração, ao choque, à impressão. E assevera:

A base psicológica do tipo metropolitano de individualidade consiste na intensificação dos estímulos nervosos, que resulta da alteração brusca e ininterrupta entre estímulos exteriores e interiores. O homem é uma criatura que procede a diferenciações. Sua mente é estimulada pela diferença entre a impressão de um dado momento e a que a precedeu. Impressões duradouras, impressões que diferem apenas ligeiramente uma da outra, impressões que assumem um curso regular e habitual e exibem contrastes regulares e habituais - todas essas formas de impressão gastam, por assim dizer, menos consciência do que a rápida convergência de imagens em mudança, a descontinuidade aguda contida na apreensão com uma única vista de olhos e o inesperado de impressões súbitas. Tais são as condições psicológicas que a metrópole cria. [...] A metrópole extrai do homem, enquanto criatura que procede a discriminações, uma quantidade de consciência diferente da que a vida rural extrai. Nesta, o ritmo da vida e do conjunto sensorial das imagens mentais flui mais lentamente, de modo mais habitual e mais uniforme. É precisamente nesta conexão que o caráter sofisticado da vida psíquica metropolitana se torna compreensível - enquanto oposição à vida de pequena cidade, que descansa mais sobre relacionamentos profundamente sentidos e emocionais ${ }^{16}$.

Tal noção de evento-choque ajuda a minar o próprio historicismo e a crença no progresso. A máxima potência do evento-choque, instituinte do tempo presente, residiria na Shoah. Ou em versões assemelhadas: nos massacres, no terror sustentado pelas ditaduras militares da América do Sul17, isto é na catástrofe. Este evento-limite delineia nossa contemporaneidade, exige nossos olhos, nossa visão, deve ser visível; e precisa ser comunicado com vistas a não se repetir. Nesta perspectiva, as obras Nunca más, publicada na Argentina pela Comissão Nacional de Desaparecidos, e Brasil, nunca mais dirigem-se do presente para o futuro, almejam falar ao futuro e ao presente, simultaneamente, com a firme proposição política de garantir a vida coletiva. O evento-limite (re)evoca o testemunho, que é ocular - aquele que viv e lá esteve -, e também a contemplação. E, ao fim e ao cabo, testemunha-se somente o evento. Não se trata de escrever uma história magistral ou moralista, na qual se ensina como enfrentar determinadas 
situações impostas pela Roda da Fortuna ou por algum desígnio metafísico ou alguma mão invisível. Antes, tenta-se não repetir o vivido, tenta-se evitar o eventolimite, a Shoah. A visibilidade deste evento-limite convoca o testemunho. Ele traz consigo a dificuldade intrínseca (muitas vezes insuportável) da literalidade, de tornar-se figurativo e crível. Aqui, discute-se a natureza do evento, seu lugar, e pede-se que suscite e lastreie o saber histórico. Através da escrita da história, da literatura de testemunho, da crítica literária, das discussões políticas e filosóficas, nesta ordem discursiva complexa e polissêmica, opera-se a memória da experiência da catástrofe e o esforço para sua não-repetição. A palavra adquire um poder terapêutico, pois necessariamente emerge para remediar a dor, evitar a repetição, e (re)introduzir o homem no âmbito da condição humana. Tal conhecimento histórico - aqui o nexo entre (in)visibilidade e imagem é capital para o debate - evita o desumano, a injustiça, a pulsão de morte como política de massa. A história abdica de qualquer tom de neutralidade - tampouco sonha com isto -, na medida em que ela atua como parte de um trabalho terapêutico entre o presente e este eventocatástrofe. $\bigcirc$ saber histórico enfrenta, assim, a necessidade de domar o trauma do passado e evitar a repetição do evento-limite.

A imagem recompõe a(s) experiência(s) do(s) passado(s), seja na filmografia que nos relalpresenta o passado, nos espaços e dispositivos museológicos, nas exposições que se alastram no cotidiano urbano, nas séries televisivas que (re)tratam o passado ${ }^{18}$. Nesse território, as imagens estabelecem uma série de liames entre si e, muitas vezes, o convencimento se dá prioritariamente por meio da imagem. Compensa indicar brevemente que, sobretudo a partir da a década de 1980, as imagens se delineiam pela velocidade. Acentua-se - no campo das imagens, em seus formatos, materialidades, dispositivos, linguagens - a sintaxe do tempo. Videogames, fotografias, cinema, artes visuais, fax, email, internet, televisão e outros acabam, em sua produção, circulação, divulgação, configurando uma expansão incessante das imagens, tal qual uma espécie de saga que persegue o vazio e, em certa medida, não o suporta. A expansão das imagens afeta a própria duração das imagens e das coisas, caracterizando uma percepção fluida do tempo e do mundo.

Aqui, o texto de Manoel ajuda demais, porque mapeia a introdução da imagem nas práticas históricas que constituem nosso regime de historicidade, que adensam a percepção do tempo, por exemplo, por meio da ruína, tanto quanto remetem às praticas do historiador ao discorrer sobre o colecionismo e o antiquário. $\bigcirc$ autor perfaz uma genealogia da imagem em nosso regime de historicidade, assinalando inclusive seus limites, ao tratar das escolhas de rememoração do passado nazista na cidade de Berlim e a opção pela manutenção da ferida aberta. Prefere-se escancarar o vazio - aquilo que as imagens e as palavras tantas vezes preenchem - como um reconhecimento da dor do outro e do terror. Nesta discussão feita por Manoel - e bem palmilhada -, acrescentaria as tensões que a imagem vai entretecendo com os textos, na medida em que a cultura material do antiquário e da coleção se choca, é cotejada - ou (re)citada - com a cultura textual ${ }^{19}$. Nesses intertextos, emergem
18. A título de explicitação: nos últimos anos, o Sistema Globo de Televisão desenvolveu a prática de exibir, entre janeiro e fevereiro, séries definidas por um tema de cunho histórico. Desde a São Paulo entre as décadas de 1920-1950 e a Semana de Arte Moderna de 1922, o processo de colonização no Brasil, o diletantismo português dos oitocentos, a era JK.

19.Ver Carlo Ginzburg (1989). 
20. Para Pomian, os semióforos "são objectos cuja aparência, a localização ou ambas mostram que estão investidos de significados" e acrescenta: "O conjunto de objectos visíveis pode assim dividir-se, de maneira aparentemente exaustiva, em cinco classes funcionais: os corpos, os restos, as coisas, os semióforos e os media. Vê-se à primeira que os três últimos correspondem a patamares de uma sucessão histórica: as coisas são bem mais antigas que os semióforos, que são por sua vez bem mais antigos que os media, não tendo começado estes últimos a distinguir-se ao mesmo tempo de uns e de outros senão a partir do século XVI. Por outro lado, um objecto não fica ligado definitivamente à classe a que pertence na origem, quanto mais não seja porque cada um corre o risco de passar a ser cedo ou tarde resto. $\mathrm{Na}$ da proíbe, por outro lado, que os objectos mudem de função no decurso da sua história: veremos mais tarde que isto acontece mais freqüentemente do que se pensa. Em especial, a degradação de um objecto entre os restos não é necessariamente definitiva, pois conhecemos os casos de reconversão dos restos e especialmente da sua promoção ao nível de semióforos.A própria irrever sibilidade do percurso conduz os corpos a outras classes de objectos". História Cultural, História dos semióforos. (Apud RIOUX; SIRINELLI, 1998, p. 92 e 71-72).

21. Márcio Seligamann-Silva (2003,p.46-47) também problematiza o papel da imaginação. Frisa a importância e a eficácia da imaginação diante da experiência da Shoah: $\mathrm{O}$ dado inimaginável da experiência concentracionária desconstrói o maquinário da linguagem. Essa linguagem entravada, por outro lado, só pode enfrentar o "real" equipada com a própria imaginação: por assim dizer, só com a arte da intraduzibilidade pode ser desafiada - mas nunca totalmente submetida.

22. Cf. Italo Calvino (1990, p. 108).

23. Idem (p. 107-108). outras compreensões históricas e/ou práticas de constituição do passado. A imagem, neste debate, é visiva e conceitual. Esta me parece uma dimensão estratégica do artigo em debate. Pois, dessa maneira, a imagem é encarada como semióforo, no âmbito da cultura histórica, que necessita ser compreendido ${ }^{20}$. A imagem explicita sem concessão as implicações da linguagem no entremeio da escrita da história, bem como seu teor estético. Se o evento-limite da Shoah tem no sublime um efeito estético que suspende, pelo terror, nossa capacidade de ajuizar, em contrapartida há que se indagar a respeito da dimensão estética do fazer historiográfico e seus efeitos. Neste ponto tão nevrálgico, o término do texto pela referência a Calvino é, parece, resultado de muita reflexão por parte de Manoel. Calvino propõe a Visibilidade, chave de seu processo de criação literária, porque implica a imaginação. Ao leitor atento, a epígrafe do artigo não passou desapercebida: Pour savoir il faut s'imaginer ${ }^{21}$

Sob hipótese, será que Manoel sugere a imaginação como forma de conhecimento imprescindível para o historiador? E aí Calvino, assumidamente filho da civilização da imagem ${ }^{22}$, pode nos ensinar:

Se incluí a Visibilidade em minha lista de valores a preservar foi para advertir que estamos correndo o perigo de perder uma faculdade humana fundamental: a capacidade de pôr em foco visões de olhos fechados, de fazer brotar cores e formas de um alinhamento de caracteres alfabéticos negros sobre uma página branca, de pensar por imagens. Penso numa possível pedagogia da imaginação que nos habitue a controlar a própria visão interior sem sufocá-la e sem, por outro lado, deixá-la cair num confuso e passageiro fantasiar, mas permitindo que as imagens se cristalizem numa forma bem definida, memorável, autosuficiente, "icástica"23. 